\title{
Fractal Features and Structural, Morphological, Optical Characteristics of Sol-Gel Derived Silica Nanoparticled Thin Films
}

\author{
B.Ö. UYSAL* AND Ö. PEKCAN
}

Kadir Has University, Faculty of Engineering and Natural Sciences, Cibali, Fatih, Istanbul 34083, Turkey

(Received January 26, 2017; in final form March 23, 2018)

\begin{abstract}
Nanostructured silica films using a simple and effective sol-gel spin coating technique were synthesized and the influence of ammonia/sol ratios on the particle size and thickness of this film was investigated. In addition, fractal dimensions of the prepared films were determined using the scattering response technique. The samples were characterized by atomic force microscopy and UV-vis spectroscopy. Comparing optical method and image analysis of atomic force microscopy micrographs, the fractal dimension of silica nanoparticled thin films was determined. The fractal dimensions of the films verified by atomic force microscopy analysis were found to be around 2.03 which is very close to the values $(2.0358,2.0325$, and 2.0335) obtained using optical method. As a result of these findings, precise determination of the nanoparticled silica thin films fractal dimension using both optical and surface analysis methods was realized.
\end{abstract}

DOI: 10.12693/APhysPolA.133.1160

PACS/topics: fractal dimension, silica, sol-gel method, size-dependence, thin films

\section{Introduction}

Research and development on silica thin films has witnessed important progresses in the last few years with regard to particle synthesis. Spray pyrolysis [1], colloidal techniques [2-5], water-in-oil microemulsion [6], micelle processing [7], hydrothermal synthesis [8] and sol-gel methods are considered to be the leading synthetic techniques $[9,10]$ in silica nanoparticle preparation. Many researchers have been a firm supporter of the sol-gel method owing to its simplicity, ease to produce uniform films, cost-effectiveness, and good applicability to the large industrial areas [11-15]. Morphology of the particles, crystallite size, and size distribution are considered as the key properties that can be tailored using various precursors, catalyst and annealing temperatures. Water, catalyst and precursor concentrations in the composition control variations in the properties [16-20]. Especially, silica nanoparticled structures were synthesized using TEOS, ammonia, water, ethanol combination in many studies in the literature [21-26]. Regarding morphology, fractal morphology in monodisperse silica particle systems has been studied by several authors [27, 28].

More recently, static light scattering (SLS) and image analysis of scanning electron microscope (SEM) photographs of aggregates were employed together with fractal analysis to characterize the agglomerate structure in films [29]. These techniques are well established and commercially available and widely used in this area. Produced results from image analysis proved that fumed silica aggregates which are used for comparison, have a two-

*corresponding author; e-mail: bozugur@khas.edu.tr level structure, namely, made out of compact aggregates and open aggregates of nanoparticles. Here, it has to be noted that this structure is not easily detected by SLS. In other words, SLS technique seems to be less accurate than image analysis method. However, since it is much less time consuming, this technique can be used in more simple cases. Even though the effect of ammonia ratio on morphological properties of nanostructures has been well-known [28, 30] and essential fractal [31,32] morphology has already been demonstrated for aggregates of silica [33, 34], the influence of catalyst material amount in composition on the optical properties (transmittance, reflectance, absorption, and scattering), particle size and implicitly thickness of the silica nanoparticled thin films (SNF) in terms of fractal analysis have not been extensively studied yet.

Therefore, in this work, the effects of ammonia/sol ratios on the particle size and thickness of the nanostructured silica films prepared by sol-gel spin coating technique were investigated. In addition, fractal dimensions of the prepared films were determined using the scattering response technique. The goal of the present work is to compare two different techniques enabling the measurement of the fractal dimension of SNF, namely optical method and image analysis of AFM micrographs.

\section{Experimental details}

\subsection{Film preparation}

The $\mathrm{SiO}_{2}$ nanoparticled sol was prepared via a Stöberlike [3] sol-gel spin coating technique which was previously reported [35]. Tetraethyl orthosilicate (TEOS) was used as a precursor chemical. $10 \mathrm{ml}$ of TEOS (99.99\% trace metals basis supplied by Sigma-Aldrich Inc.), $40 \mathrm{ml}$ of ethanol and $20 \mathrm{ml}$ of deionized water 
were mixed. Then various amounts $(0.109,0.174,0.218$, $0.436,0.873 \mathrm{ml}$ ) of ammonia solutions were added as a catalyst, denominated as SNF1, SNF2, SNF3, SNF4, and SNF5, respectively. The sols were spin coated on corning (2947) glasses at $1500 \mathrm{rpm}$ for $30 \mathrm{~s}$. The coatings were heat treated for $2 \mathrm{~h}$ in air at $450^{\circ} \mathrm{C}$ employing a microprocessor-controlled (CWF 1100) furnace.

\subsection{Characterizations}

The determination of morphology of the films was carried out using an atomic force microscope (AFM) in dynamic mode (Model SPM-9500, Shimadzu Corp.). Optical transmittance, reflectance and absorbance data of the films were produced using a UV-vis spectrophotometer (Perkin-Elmer LAMBDA 900 integrating sphere system). Additionally, the thicknesses of the films were also measured using this spectrophotometer.

\section{Results and discussion}

\subsection{Surface morphology of the films}

The influence of the amount of ammonia solution on the surface morphology of SNF is presented via threedimensional (3D) AFM images in Fig. 1a. It is obvious to see that all the films have a granular structure and consist of uniform, close-packed particle clusters. This figure can be interpreted that the $\mathrm{SiO}_{2}$ particles are uniformly distributed over the whole surface of the films due to well-synthesized sol. Furthermore, according to the AFM images of SNF, one can observe that the particle size increases when the amount of ammonia in sol increases. Here, it is worth mentioning that the particle size monitored with AFM refers to the lateral feature size, namely lateral diameter of the agglomerated granular structures. As a result, particle size is not correlated with the crystallite size due to amorphous structure of films heat treated at $450^{\circ} \mathrm{C}$. SPM Manager Program was used to evaluate the average particle size, roughness values, and fractal dimensions of the films. The calculated average particle size values for films with different amount of ammonia are listed in Table I. Particle size is directly proportional to the amount of catalyst material, ammonia, in that the catalyst material lowers the activation energy by altering the pathway and shortening the gelation time as mentioned in the literature, for both silica [36-41] and other metal oxide nanostructures [42, 43]. As expected, $z$-range observations are in agreement with the particle size values.

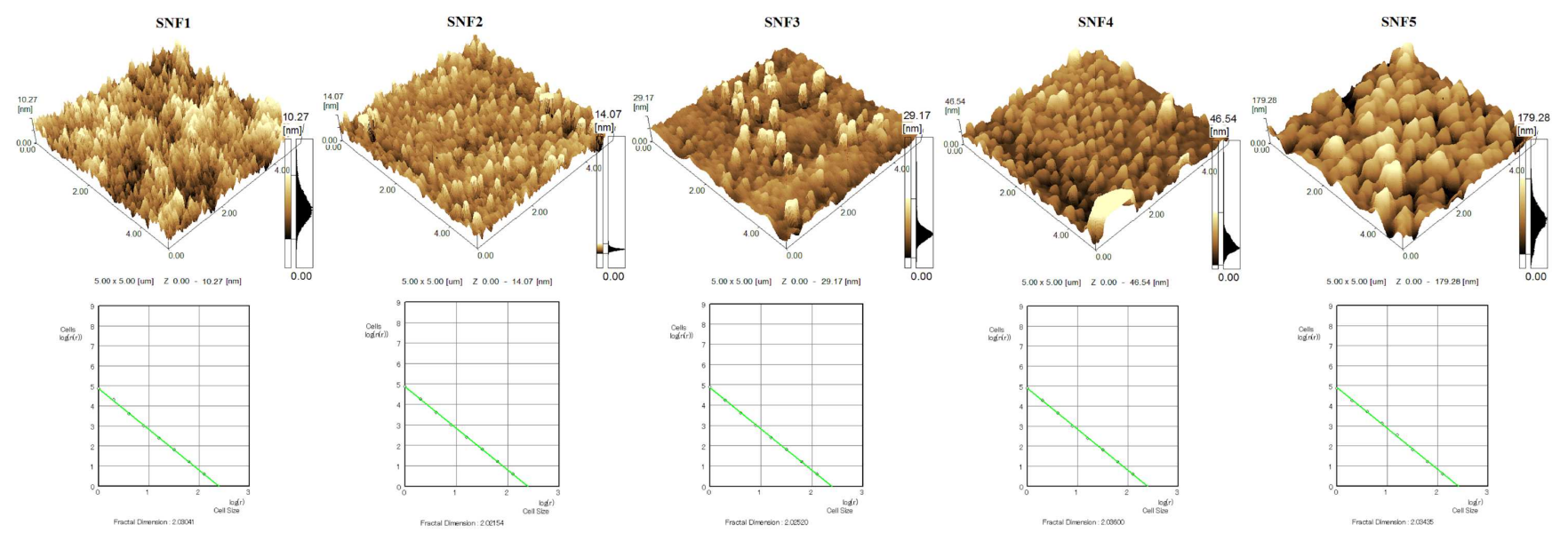

Fig. 1. Three-dimensional (3D) AFM images of silica nanofilms (a) for different amounts of ammonia: 0.109, 0.174, $0.218,0.436,0.873 \mathrm{ml}$ at heat treatment temperature of $450{ }^{\circ} \mathrm{C},(\mathrm{b})$ the fractal dimensions of the films calculated based on the slope of the logarithmic plot of number of cells $n(r)$ versus cell size $r$.

TABLE I

AFM and spectrophotometer analysis results of nanostructured silica thin films with different volume ratio of ammonia/sol.

\begin{tabular}{c|c|c|c|c|c}
\hline \hline Film & $\begin{array}{c}\text { Ammonia/sol } \\
\text { volume ratio }\end{array}$ & Thickness [nm] & $\begin{array}{c}\text { Particle } \\
\text { size [nm] }\end{array}$ & $\begin{array}{c}\text { Scattering } \\
\text { intensity }\end{array}$ & $\begin{array}{c}\text { Fractal dimension } \\
\text { verified } \\
\text { byM Manager }\end{array}$ \\
\hline SNF1 & $1.45 \times 10^{-3}$ & 49 & 19 & 0.002 & $2.03041 \pm 0.0183$ \\
SNF2 & $2.32 \times 10^{-3}$ & 71 & 32 & 0.006 & $2.02154 \pm 0.0172$ \\
SNF3 & $2.91 \times 10^{-3}$ & 125 & 48 & 0.009 & $2.02520 \pm 0.0179$ \\
SNF4 & $5.82 \times 10^{-3}$ & 225 & 75 & 0.037 & $2.03600 \pm 0.0188$ \\
SNF5 & $1.16 \times 10^{-2}$ & 340 & 158 & 0.168 & $2.03435 \pm 0.0185$
\end{tabular}


Figure 1b represents the fractal dimensions of the films calculated based on the slope of the logarithmic plot of number of cells, $n(r)$, versus cell size $r$. Fractal analysis tool of SPM Manager Program is based on the cube counting method $[44,45]$ derived from a definition of boxcounting method to measure fractal dimension. The algorithm works on the $z$-surface by taking the number of cells that contain at least one pixel of the image. The slope of the plot of $\log (n(r))$ versus $\log (r)$ gives the fractal dimension directly [46]. The measured fractal dimension values are given in Table I. They are very close to each other. The slight differences between them are only visible in the second digit after the decimal.

\subsection{Fractal analysis via optical studies}

In order to find the scattering response of the films, transmittance, reflectance and absorbance modulations were measured by the UV-vis spectrophotometer in a spectral range of $300-1000 \mathrm{~nm}$. Figures 2 and 3 depict
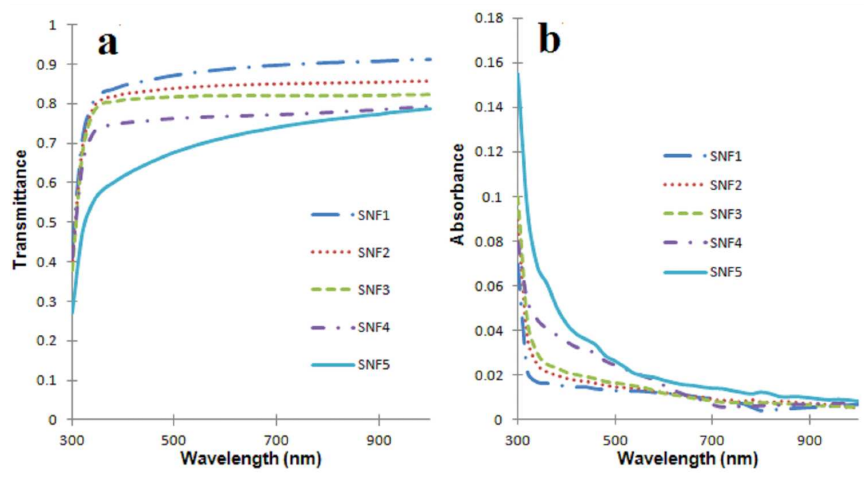

Fig. 2. UV-vis (a) transmission, (b) absorption spectra of silica nanofilms for different ammonia volume ratios.
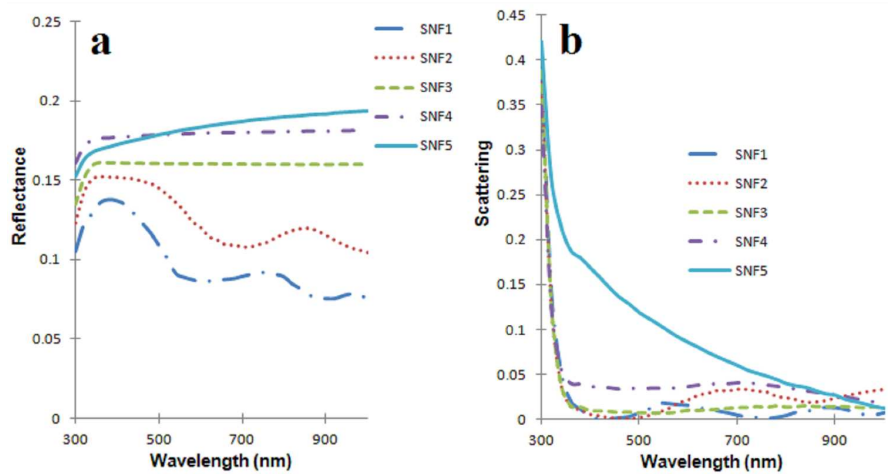

Fig. 3. The influence of ammonia/sol volume ratios on (a) reflection and (b) scattering response of silica nanofilms.

the effect of the ammonia solution's amount on these measurements of the SNF with respect to wavelength. Transmittance values of the films were decreased with the increase of ammonia/sol ratios as shown in Fig. 2a. The decrease in the volume ratio of ammonia/sol produces a blue shift in the absorbance spectra of the films in Fig. 2b due to quantum size effect. Additionally, the difference in the absorption edge is related to the Burstein-Moss effect because of the increase of water concentration in the sol. Some part of the incident light absorbed by and some part of it transmitted through the film depended on its thickness. The scattering intensity of the films at $400 \mathrm{~nm}$ increases, when the ratio of ammonia/sol increases as seen in Fig. 3. The calculated scattering intensity and thickness values are provided in Table I.

The thickness values of the films increased with the increase of amount of ammonia in sol. This is not surprising because the increase in the thickness values of the films is in agreement with an increase of particle size observed by AFM measurements.
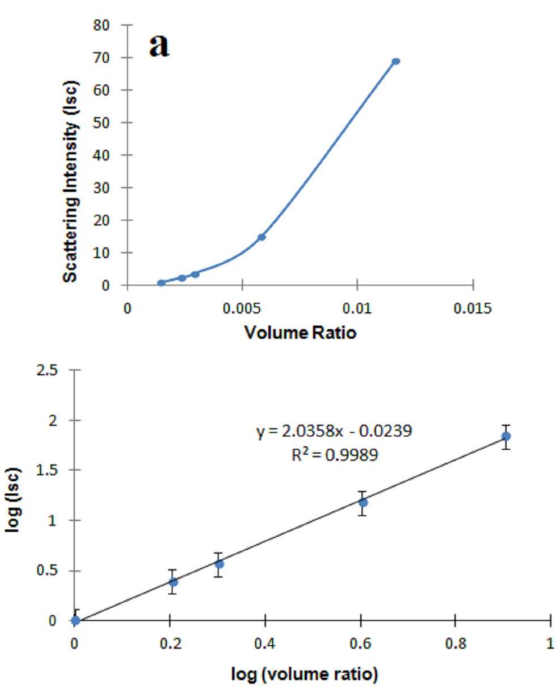

Fig. 4. The plots of scattering intensity versus (a) volume ratio, (b) thickness, and (c) particle size on linear and logarithmic scales.
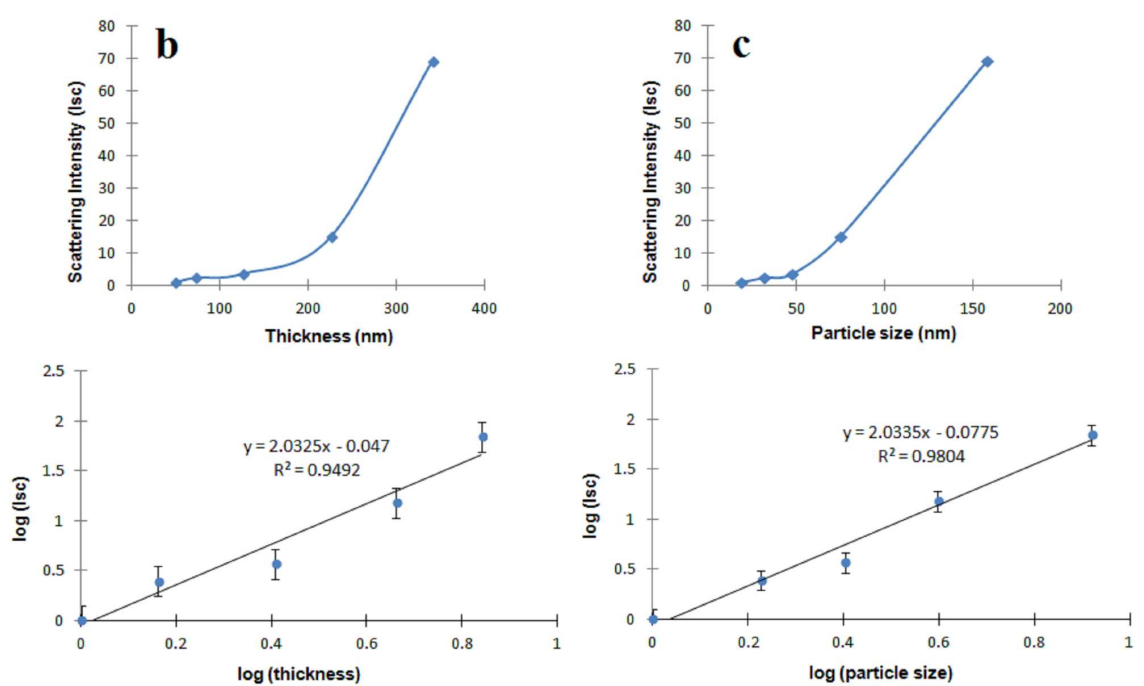
The plots of scattering intensity versus volume ratio, thickness and particle size on linear and logarithmic scales are shown in Fig. 4a-c, respectively. The optical measurements for films display an increase in scattering by increasing these quantities.

It has been well established that fractals have selfsimilar structures that can be characterized by a single parameter, the fractal dimension $D$. If $D=2$, the film has a planar [47] and smooth surface morphology like a substrate, as exemplified in [48] and [49]. The dependence of scattering intensity $I_{s c}$ on the ammonia/sol volume ratio $V$, the thickness $T$ and the particle size $S$ in the SNF films, can be suggested by the following equations [50, 34]:

$$
I_{s c}=(V)^{D}, \quad I_{s c}=(T)^{D}, \quad I_{s c}=(S)^{D}, \quad(1 \mathrm{a}, \mathrm{b}, \mathrm{c})
$$
where $D$ is the fractal dimension of the film and $I_{s c}$ is the scattering intensity of films. Here it is assumed that $V, T$, and $S$ values are proportional to the scattering centers in the film presenting power law dependency as given in Eqs. (1a, b) and (c). It is obvious that $I_{s c}$ is proportional to scattering centers of the films under consideration. In Fig. $4 \mathrm{a}-\mathrm{c} \log -\mathrm{log}$ plot of normalized $I_{s c}$ intensities are plotted versus $V, T$, and $S$, respectively. The fractal dimensions are produced from slopes of the logarithmic plots and given in Table II.

\section{TABLE II}

Fractal dimensions of the nanostructured silica thin films measured by optical methods.

\begin{tabular}{l|c}
\hline \hline \multicolumn{1}{c|}{ Method } & Fractal dimension \\
\hline volume ratio $V$ & 2.0358 \\
thickness $T$ & 2.0325 \\
particle size $S$ & 2.0335
\end{tabular}

\section{Conclusion}

The nanoparticled silica thin films were synthesized by sol-gel spin coating process. Different particle sizes were obtained using various amounts $(0.109,0.174,0.218$, $0.436,0.873 \mathrm{ml})$ of ammonia solutions at the same annealing temperature of $450{ }^{\circ} \mathrm{C}$. The optical studies revealed that the scattering intensity of the films decreased with increase of wavelength. Moreover, the scattering intensity of SNF increased with the volume ratio of ammonia/sol. The absorption edge of the SNF shifted to longer wavelengths with an increase in amount of ammonia solution due to the quantum confinement and the BurnsteinMoss effects of nanoparticles. Both optical measurements and SPM Manager Program results of SNF confirm the change of the particle size with the amount of ammonia. The fractal dimension $D$ of the SNF measured by SPM was found to be around 2.03 which is very close to the $D$ values $(2.0358,2.0325$, and 2.0335$)$ produced by optical method. These extremely small differences are within the error limits. The $D$ values strongly support the structure of SNF film having planar and smooth surface morphology.
In summary, this study indicates that it is possible to determine the fractal dimension of the nanoparticled silica thin films precisely using both optical and surface analysis methods.

\section{Acknowledgments}

The authors would like to thank Materials Science Laboratory employees of SabanciUniversity for the morphological analysis.

\section{References}

[1] H.D. Jang, H. Chang, Y. Suh, K. Okuyama, Curr. Appl. Phys. 6, e110 (2006).

[2] Y. Huang, J.E. Pemberton, Coll. Surf. A Physicochem. Eng. Asp. 360, 175 (2010).

[3] W. Stöber, A. Fink, J. Coll. Interface Sci. 26, 62 (1968).

[4] S.K. Park, K.D. Kim, H.T. Kim, Coll. Surf. A Physicochem. Eng. Asp. 197, 7 (2002).

[5] X.D. Wang, Z.X. Shen, T. Sang, X.B. Cheng, M.F. Li, L.Y. Chen, Z.S. Wang, J. Coll. Interface Sci. 341, 23 (2010).

[6] S. Santra, P. Zhang, K. Wang, R. Tapec, W. Tan, Anal. Chem. 73, 4988 (2001).

[7] X. Lv, L. Zhang, F. Xing, H. Lin, Micropor. Mesopor. Mater. 225, 238 (2016).

[8] A.B. Corradi, F. Bondioli, A.M. Ferrari, B. Focher, C. Leonelli, Powder Technol. 167, 45 (2006).

[9] S. Duhan, S. Devi, M. Singh, J. Rare Earths 27, 83 (2009).

[10] M. Marini, B. Pourabbas, F. Pilati, P. Fabbri, Coll. Surf. A Physicochem. Eng. Asp. 317, 473 (2008).

[11] M. Jafarzadeh, I.A. Rahman, C.S. Sipaut, J. Sol-Gel Sci. Technol. 50, 328 (2009).

[12] G.M. Pajonk, Coll. Polym. Sci. 281, 637 (2003).

[13] K. Ishizaki, S. Komarneni, M. Nanko, in: Porous Materials, Vol. 4 of the series Materials Technology Series, Springer, USA 1998, p. 67.

[14] S. Chang, M. Lee, W. Kim, J. Coll. Interface Sci. 286, 536 (2005).

[15] G.H. Bogush, C.F. Zukoski, J. Coll. Interface Sci. 142, 1 (1991).

[16] J. Li, L. Chen, Z. Zhang, C. Jiao, J. Wuhan Univ. Technol. - Mater. Sci. Ed. 29, 478 (2014).

[17] K.S. Rao, K. El-Hami, T. Kodaki, K. Matsushige, K. Makino, J. Coll. Interface Sci. 289, 125 (2005).

[18] Ö. Kesmez, E. Burunkaya, N. Kiraz, H.E. Çamurlu, M. Asiltürk, E. Arpaç, J. Non-Cryst. Solids 357, 3130 (2011).

[19] H.C. Wang, C.Y. Wu, C.C. Chung, M.H. Lai, T.W. Chung, Ind. Eng. Chem. Res. 45, 8043 (2006).

[20] S.K. Park, K.D. Kim, H.T. Kim, Coll. Surf. A 197, 7 (2002).

[21] D.C.L. Vasconcelos, W.R. Campos, V. Vasconcelos, Mater. Sci. Eng. A - Struct. Mater. Prop. Microstruct. Process. 334, 53 (2002). 
[22] W. Wang, B. Gu, J. Phys. Chem. B 109, 22175 (2005).

[23] I.A. Rahman, P. Vejayakumaran, C.S. Sipaut, J. Ismail, M. Abu Bakar, R. Adnan, C.K. Chee, Coll. Surf. A 294, 102 (2007).

[24] K.S. Kim, J.K. Kim, W.S. Kim, Ceram. Int. 28, 187 (2002).

[25] J.W. Yoo, D.S. Yun, H.J. Kim, J. Nanosci. Nanotechnol. 6, 3343 (2006).

[26] J. Li, L.X. Chen, Z.M. Zhang, C.B. Jiao, Adv. Mater. Res. 560-561, 462 (2012).

[27] R. Watanabe, T. Yokoi, E. Kobayashi, Y. Otsuka, A. Shimojima, T. Okubo, T. Tatsumi, J. Coll. Interface Sci. 360, 1 (2011).

[28] C. Oh, S.B. Shim, Y.G. Lee, S.-G. Oh, Mater. Res. Bull. 46, 2064 (2011).

[29] N. Ibaseta, B. Biscans, Powder Technol. 203, 206 (2010).

[30] L.P. Singh, S.K. Bhattacharyya, R. Kumar, G. Mishra, U. Sharma, G. Singh, S. Ahalawat, Adv. Coll. Interface Sci. 214, 17 (2014).

[31] B.B. Mandelbrot, Phys. Scr. 32, 257 (1985).

[32] X. Zhang, Y. Xu, R.L. Jackson, Tribol. Int. 105, 94 (2017).

[33] B.M. Smirnov, Phys. Rep. 188, 1 (1990).

[34] J.E. Martin, A.J. Hurd, J. Appl. Crystallogr. 20, 61 (1987).

[35] B. Özuğur Uysal, F.Z. Tepehan, J. Sol-Gel Sci. Technol. 63, 177 (2012).

[36] H.M. Lim, H.C. Shin, S.H. Huh, S.H. Lee, Solid State Phenom. 124-126, 667 (2007).
[37] V.I. Boev, A. Soloviev, C.J.R. Silva, M.J.M. Gomes, J. Pérez-Juste, I. Pastoriza-Santos, L.M. Liz-Marz, in: Nanostructured Materials for Advanced Technological Applications, part of the series NATO Science for Peace and Security Series B: Physics and Biophysics, Springer, Netherlands, 2009, p. 245.

[38] M. Fertani-Gmati, K. Brahim, I. Khattech, M. Jemal, Thermochim. Acta 594, 58 (2014).

[39] M. Toki, T. Takeuchi, S. Miyasita, S. Kanbe, J. Mater. Sci. 27, 2857 (1992).

[40] M. Darbandi, UV-VIS and Photoluminescence Spectroscopy for Nanomaterials Characterization, Springer, Berlin 2013, p. 431.

[41] G.-L. Davies, A. Barry, Y.K. Gunko, Chem. Phys. Lett. 468, 239 (2009).

[42] Z.-X. Tang, L.-E. Shi, Eclecita Quim. 33, 15 (2008).

[43] L. Bian, S.P. Wang, X.B. Ma, Kinet. Catal. 55, 763 (2014).

[44] C. Douketis, Z. Wang, T.L. Haslett, M. Moskovits, Phys. Rev. B 51, 11022 (1995).

[45] W. Zahn, A. Zösch, Fresenius J. Anal. Chem. 365 168 (1999).

[46] W. Zahn, A. Zösch, Fresenius J. Anal. Chem. 358, 119 (1997).

[47] S. Sadi, A. Paulenova, P.R. Watson, W. Loveland, Nucl. Instrum. Methods Phys. Res. A 655, 80 (2011).

[48] A. Mannelqvist, M.R. Groth, Appl. Phys. A 73, 347 (2001).

[49] C.G. Sonwane, S.K. Bhatia, N.J. Calos, Langmuir 15 , 4603 (1999).

[50] J. Bastide, L. Leibler, J. Prost, Macromolecules 23 , 1821 (1990) 